\title{
NO JOGO DO MERCADO: O CASO DE UMA STARTUP GAÚCHA
}

\author{
Dusan Schreiber* \\ dusan@feevale.br \\ Cristiano Max Pereira Pinheiro* \\ maxrs@feevale.br \\ Marsal Ávila Alves Branco* \\ marsal@feevale.br \\ Cláudia Simone Antonello** \\ claudia.antonello@ufrgs.br \\ Deise Land* \\ deise.sland@gmail.com \\ *Universidade Feevale - Novo Hamburgo, RS / Brasil
}

**Universidade Federal do Rio Grande do Sul - Porto Alegre, RS / Brasil

http://dx.doi.org/10.1590/1413-2311.0442015.54863

Recebido em 14/04/2015

Aprovado em 04/07/2016

Disponibilizado em 31/08/2016

Avaliado pelo sistema "double blind review"

Revista Eletrônica de Administração

Editora-chefe: Aurora Zen

ISSN 1413-2311 (versão "on line")

Editada pela Escola de Administração da Universidade Federal do Rio Grande do Sul.

Periodicidade: Quadrimestral

Sistema requerido: Adobe Acrobat Reader

\section{RESUMO}

O empreendedorismo tem recebido estímulo na maioria dos países por sua relevância econômica e social, em virtude de seu potencial de gerar emprego e renda. Mais recentemente, com o surgimento e a consolidação dos segmentos econômicos que representam a indústria criativa, o apoio tornou-se mais visível e evidente. A principal característica destas atividades consiste no valor agregado a partir do uso intensivo de competências técnicas e artísticas, baseadas no talento individual, dependente mais de inteligência, aptidão, habilidades e capacidades específicas individuais e coletivas, do que de investimento em bens de capital. A criação e o desenvolvimento de jogos digitais é considerado um dos setores mais representativos e promissores da indústria criativa, no entanto o correspondente mercado, apesar de recente, é complexo. Ele não exige apenas competência técnica específica, sendo requerida também capacidade de coordenação e de desenvolvimento relacional com potenciais parceiros para viabilizar economicamente o 


\title{
NO JOGO DO MERCADO: O CASO DE UMA STARTUP GAÚCHA
}

lançamento do jogo no mercado. O caso de ensino aqui apresentado é verídico e evidencia alguns dos desafios com os quais os empreendedores deste segmento econômico se deparam. $\mathrm{O}$ caso oferece importantes contribuições tanto para gestores como para potenciais empreendedores, bem como oportuniza elementos para promover discussões em aulas nas disciplinas de empreendedorismo, marketing, estratégia e gestão de pessoas.

Palavras-chave: indústria criativa; empreendedorismo; estratégia.

\section{IN THE MARKET'S GAME: THE CASE OF A STARTUP}

\begin{abstract}
Entrepreneurship has received stimulus in most countries due to the economic and social relevance, as of the potential to generate employment and income. More recently, with the emergence and consolidation of economic segments that represent the creative industry, the governamental support has become more visible and evident. The main feature of these activities is the added value that comes from the intensive use of technical and artistic skills, based on individual talent, more dependent on intelligence, aptitude, skills and individual and collective specific skills, more than of the investment in financial capital. The creation and development of games is considered one of the most representative and promising sectors of the creative industry. However this market, although recent is complex. Not only requires specific expertise, requiring also the capacity for coordination and ability of the relational development with potential partners to turn economically viable the release of the game in the market. The teaching case presented here is true and presents some of the challenges that entrepreneurs face in this economic segment. The case offers important contributions both to managers or potential entrepreneurs and gives opportunity of advancing discussion in classes in entrepreneurship courses, marketing, strategy and people management.
\end{abstract}

Keywords: creative industry; entrepreneurship; strategy.

\section{IN JUEGO OF MERCADO: EL CASO DE UNA STARTUP}

\begin{abstract}
RESUMEN
Emprendimiento ha recibido estímulo en la mayoría de los países de la importancia económica y social, debido a su potencial para generar empleo e ingresos. Más recientemente, con el surgimiento y consolidación de los segmentos económicos que representan a la industria creativa, el apoyo se ha hecho más visible y evidente. La característica principal de estas actividades es el valor añadido de la utilización intensiva de las habilidades técnicas y artísticas, basado en el talento individual, más dependiente de inteligencia, aptitudes, habilidades y destrezas específicas individuales y colectivas, que la inversión en bienes de capital. La creación y desarrollo de juegos digitales es considerado uno de los sectores más representativos y prometedores de la industria creativa. Sin embargo este mercado, aunque reciente es compleja. No sólo requiere experiencia específica, que requiere también la capacidad de coordinación y el desarrollo de relaciones con socios potenciales para facilitar económicamente el lanzamiento del juego en el mercado. El caso de enseñanza que se presenta aquí es verdadera y presenta algunos de los desafíos que enfrentan los empresarios
\end{abstract}

REAd | Porto Alegre - Edição 84 - N 2 - Maio / Agosto 2016 - p. 543 - 571 


\section{Dusan Schreiber, Cristiano Max Pereira Pinheiro, Marsal Ávila Alves Branco, Cláudia} Simone Antonello \& Deise Land

de este segmento económico. El caso ofrece importantes contribuciones tanto para los administradores como los empresarios potenciales y le da la oportunidad de avanzar en la discusión en las clases en los cursos de iniciativa empresarial, marketing, estrategia y gestión de personas.

Palabras-clave: industria creativa; la iniciativa empresarial; estrategia.

\section{INTRODUÇÃO}

Abrir seu próprio negócio e deixar de ser um empregado é, comprovadamente, o sonho de $44 \%$ dos brasileiros. Conquistar a independência, autodeterminar-se e ter a perspectiva de ganhar mais, assegurando um futuro melhor para si e para toda a sua família são os motivos mais citados pela maioria dos entrevistados de inúmeras pesquisas realizadas sobre o tema empreendedorismo no Brasil (SEC, 2011; GEM, 2012).

Estes também eram, entre outros, os motivos destacados por Cristiano e Marsal, dois profissionais que diferiam do perfil da maioria de outros empreendedores brasileiros, por serem detentores tanto de sólida experiência profissional como de formação acadêmica em nível de doutorado. Com formação em publicidade e comunicação social, ambos foram contratados, no ano 2007, por uma universidade privada de grande porte, localizada na região metropolitana de Porto Alegre, para integrar a equipe de docentes dos cursos de comunicação. Naquele momento, eles nem pensavam em iniciar um negócio próprio.

Tudo começou mais ou menos assim ...

\section{PERCEPÇÃO DA OPORTUNIDADE}

Entre idas e vindas da capital até a Universidade, pela qual tinham sido contratados, Cristiano e Marsal foram se conhecendo, encontrando afinidades e interesses comuns. Isto contribuiu tanto para a construção de uma relação de amizade como para o compartilhamento de ideias, por exemplo, a de propor para a instituição a criação de um curso de jogos digitais. $\mathrm{O}$ que fora originalmente apenas uma ideia transformou-se em um projeto, o qual foi acolhido pela instituição de ensino e, alguns anos depois, operacionalizado, com o curso passando a integrar o rol de mais de sessenta cursos de graduação oferecidos ao mercado, no ano 2008.

Tratava-se, em sua essência, de um curso pioneiro e inovador, que pretendia suprir algumas das demandas que os dois profissionais tinham percebido no mercado, através de suas experiências anteriores à carreira acadêmica. Tal percepção foi confirmada durante a 


\section{NO JOGO DO MERCADO: O CASO DE UMA STARTUP GAÚCHA}

operacionalização do curso de jogos digitais, quando diversas empresas, especialmente agências de publicidade, passaram a contatar a Universidade, com a finalidade de contratar serviços e alunos em formação. A maioria das demandas era repassada para Cristiano e Marsal, que começaram a ser sistematicamente chamados de 'consultores', contribuindo para a reflexão sobre a oportunidade de abertura de uma empresa focada em jogos digitais.

No final do primeiro ano do curso de jogos digitais, Cristiano e Marsal realizaram consultoria para o Banco Sicredi, mediada pela agência de publicidade Competence. Nesta ocasião, os dois profissionais propuseram ao banco a implantação de uma estratégia de comunicação através do uso de jogos. A proposta foi aceita e o projeto executado, porém não pelos mesmos profissionais, visto que eles não tinham uma empresa formalizada para tal fim. Esse foi o momento em que decidiram formalizar o negócio.

Cristiano era quem tinha mais experiência como empreendedor, pois fora sócio na empresa de seu pai, uma editora de livros, que também publicava um jornal e oferecia cursos específicos na área de segurança pública. Desde muito cedo, ele ajudou o pai a empreender esse negócio, que continua em funcionamento. Quando jovem, ainda como sócio da editora de seu pai, abriu com alguns colegas uma pequena agência de publicidade, nos moldes de bureau de serviços gráficos, basicamente para atender clientes do bairro em que morava.

Segundo Cristiano, a experiência empreendedora mais relevante e que deu respaldo para iniciar, com seu amigo, a nova empresa de jogos foi a que ele teve, antes de ingressar na Universidade, na "Engenho de Ideias", uma agência de propaganda que ele abriu em 2001 e da qual foi sócio até 2007. Cristiano considera esta experiência profissional como mais importante sob o ponto de vista de maturidade empreendedora, pois, através dela, teve a oportunidade de lidar com todos os detalhes de um negócio. Ele iniciou praticamente com nenhum capital e atingiu, cinco anos após (em 2006), uma posição de destaque no mercado, contando com 15 colaboradores e com dois dos três sócios vivendo do pro-labore do empreendimento. Cristiano deixou a agência no ano seguinte, devido à mudança para Novo Hamburgo para assumir a Coordenação dos Cursos de Comunicação Social. Apesar de ser mestre, doutor, ele sempre considerou importante manter relação com o mercado.

\section{FASE DA INCUBAÇÃO}

Em dezembro de 2007, foi encaminhado o registro da empresa, com razão social "Ilinx Entretenimento". A escolha do nome Ilinx não ocorreu ao acaso. Ilinx representa uma REAd | Porto Alegre - Edição 84 - № 2 - Maio / Agosto 2016 - p. 543 - 571 


\section{Dusan Schreiber, Cristiano Max Pereira Pinheiro, Marsal Ávila Alves Branco, Cláudia Simone Antonello \& Deise Land}

das categorias de jogos propostas pelo teórico Roger Caillois, ela inclui os jogos que lidam com vertigem, como montanha russa, roleta russa, brincadeiras de girar, cambalhotas, enfim coisas divertidas, que, de certa forma, refletem o conceito da empresa. Era para ser uma empresa simples, com a proposta de fazer jogos, atender agências de publicidade, entregar interatividade, diversão e tecnologia. Por terem ciência das empresas concorrentes no segmento, os sócios pretendiam se estabelecer por um preço mais acessível, além de resolver e criar soluções que outros não teriam como fazer, pois os jogos eram interpretados por ambos como uma linguagem e não apenas como um produto.

Usar o sobrenome Entretenimento visava assegurar a liberdade criativa para conceber e entregar diversos tipos de soluções. A ideia da liberdade era importante para os dois, a fim de não deixá-los presos apenas aos jogos digitais, permitindo-lhes fazer jogos de tabuleiros, criar tapetes interativos, ou seja, produzir e entregar aquilo deque o cliente tivesse necessidade para propiciar uma ótima experiência a seu público. Esse era o conceito. No entanto, o sonho mesmo era produzir jogos de entretenimento para consoles e lojas on line. A visão de empresa propunha aproveitar a oportunidade existente em virtude da condição que tinham de apoio institucional, de contatos no mercado, para, mais adiante, virem a trabalhar com propriedade intelectual.

A empresa foi instalada, inicialmente, na incubadora da Universidade. Os primeiros três colaboradores foram selecionados entre os alunos do curso de Jogos Digitais. Apesar de uma série de vantagens que a incubação oferecia, como baixo custo de instalação, suporte de consultores e equipe administrativa, a decisão de iniciar na incubadora trouxe alguns problemas e dificuldades. Dentre eles, destacou-se a questão logística, visto que a incubadora da Universidade não estava localizada no mesmo município, situando-se em uma área não atendida por linhas de ônibus, distante vários quilômetros de qualquer centro urbano.

A dificuldade logística, em virtude da localização da incubadora da Universidade, exigia do sócio Cristiano, que tinha se mudado para a cidade mais próxima, prestar serviço de transporte a todos os funcionários. Isto se refletia negativamente na qualidade de vida dele e de sua esposa, que começara a colaborar com o projeto, assumindo a função de gestora administrativa e financeira. Por outro lado, o apoio da Universidade ao projeto e a disponibilidade da infraestrutura da incubadora mostravam-se muito importantes para o início da empresa, tendo, inclusive, possibilitado o, fechamento dos primeiros contratos com o mercado.

Tratava-se de projetos que utilizavam, para fins de comunicação, dispositivos de 


\section{NO JOGO DO MERCADO: O CASO DE UMA STARTUP GAÚCHA}

realidade aumentada - tecnologia que a equipe aprendeu a dominar com facilidade e que lhe deu algum fôlego financeiro para o início da operação. As principais dificuldades que a empresa enfrentou, na percepção dos próprios sócios, foram a inexperiência da equipe (inclusive dos sócios); a falta de tempo para se dedicarem ao negócio; a carência, no mercado local, da cultura de uso de jogos. Uma das principais consequências disso foi a incapacidade de dimensionar o tamanho dos projetos e estabelecer preços.

No que diz respeito à equipe, ficou evidente, em alguns meses, que ela não tinha condições de dar conta da produção demandada. De fato, nenhum dos colaboradores possuía experiência profissional, sendo o primeiro emprego de todos eles. Essa característica se sobrepunha, somando-se ao fato de que os dois sócios não podiam se dedicar muito tempo à empresa devido às responsabilidades assumidas com a Universidade, onde ambos eram coordenadores de curso. Desta forma, os dois sócios consolidavam, cada vez mais, a impressão de que as coisas não funcionavam como imaginado originalmente. Algumas vezes, os dois tiveram que trabalhar nos projetos, produzindo arte, código e demais aspectos requeridos para a entrega do produto, no entanto tal demanda só podia ser suprida em horários escassos e alternativos.

A situação começou a mudar quando, em 2009, a empresa produziu o primeiro jogo, um webgame para ser utilizado como atração de estudantes para a página do vestibular da Universidade. A experiência de ter produzido o jogo e o aporte financeiro decorrente da venda foram bastante importantes naquele momento, pois eles conseguiram redirecionar os esforços para a produção de jogos mais complexos. Até aquele momento, a empresa realizara seis trabalhos e o custo fixo mensal estava em torno de $\mathrm{R} \$ 5.000,00$.

\section{SAÍDA DA INCUBADORA E A PROFISSIONALIZAÇÃO DA GESTÃo}

As dificuldades logísticas decorrentes da localização geográfica da incubadora estavam, cada vez mais, afetando o ritmo produtivo da empresa, levando os sócios à decisão de buscar outro local. Depois de alguns meses de pesquisa e análise, a empresa foi transferida para uma casa alugada, localizada ao lado do campus da Universidade onde os dois sócios trabalhavam. A decisão foi tomada com base no entendimento de que esta forma resolveria tanto o problema dos funcionários (todos alunos da Universidade) como aliviaria a agenda dos dois sócios, funcionários da instituição. Neste aspecto, de fato, a mudança foi benéfica e a empresa continuava contando com as vantagens de incubação, pois permanecia vinculada à

REAd | Porto Alegre - Edição 84 - N 2 - Maio / Agosto 2016 - p. 543 - 571 


\section{Dusan Schreiber, Cristiano Max Pereira Pinheiro, Marsal Ávila Alves Branco, Cláudia Simone Antonello \& Deise Land}

incubadora, mas na modalidade de incubação externa.

A proximidade com a Universidade adquiria importância porque os dois sócios mantinham postos de produção (em gerência e arte) dentro da equipe de desenvolvimento. A experiência de ter produzido o primeiro jogo para a Universidade foi significativa não apenas pela experiência em si e pelo aporte de recursos financeiro, mas também por contribuir para o aprimoramento do modelo de produção, pois, pela primeira vez, houve a contratação de freelancers, o que passaria a ser cada vez mais frequente. A relevância do aprimoramento do modelo de produção estava na transferência do conhecimento externo para dentro da organização. Os dois sócios decidiram então contratar um gerente de projeto, com remuneração correspondente ao salário de mercado, no entanto muito alto para uma pequena empresa,.

Analisando a venda do primeiro jogo, sob outra perspectiva, os sócios entendem que o, naquele momento, ele representou um caso de produção interessante, mas com resultados abaixo do esperado para a instituição. Um dos motivos disso foi a expectativa otimista quanto à repercussão da ferramenta para atração de público-alvo, baseado no pressuposto de que a simples publicação de um jogo faria com que multidões de fãs visitassem o site, algo que, em um mundo com expressiva quantidade de ofertas e opções, não se concretiza.

Para a Ilinx Entretenimentos, o case oportunizou acesso a um número maior de agências de publicidade e a novos contratos de trabalho, o que contribuiu para o aumento de receita operacional. A empresa conseguia obter receita suficiente para manter a operação, mas errava no processo de cálculo da estimativa de custos de produção. Além da inexperiência, um dos motivos desta situação estava na qualidade da equipe contratada, cujo trabalho exigia muito retrabalho, consequentemente, aumentando os custos.

Em certo momento, não havia mais como continuar gerenciando a situação da forma adotada. Os sócios decidiram promover uma reestruturação interna, a começar pela equipe. Os três funcionários iniciais foram desligados. uma nova equipe, mais qualificada, mas também bastante mais cara, foi contratada. Em contrapartida, verificou-se a melhoria da qualidade de produtos e serviços. A qualidade estética e técnica de produtos deu um salto de qualidade e os dois sócios sentiram, pela primeira vez, que a empresa estava ficando pronta para competir com as desenvolvedoras mais tradicionais e de maior porte, objeto de admiração de ambos.

Nesse mesmo período, foi contratada uma secretária para fazer o atendimento a clientes, dar o suporte administrativo, secretariar ambos os sócios. A entrada desta nova colaboradora evidenciou a inadequada divisão de tarefas na área administrativa e financeira, 


\section{NO JOGO DO MERCADO: O CASO DE UMA STARTUP GAÚCHA}

especialmente entre ela e a esposa do sócio Cristiano. Ficou igualmente evidente a necessidade de maior esforço de prospecção comercial, tarefa que coube ao sócio Marsal, em virtude de ele ainda residir em Porto Alegre, onde se localizava a maior quantidade de agências e de sedes de empresas com potencial para contratar os serviços da Ilinx. Para fechar um contrato, cada vez mais se fazia necessário maior número de prospecções, no mínimo entre vinte e trinta.

Para conseguir trabalhos, os preços eram negociados com muita flexibilidade, a tal ponto que, frequentemente, os contratos eram fechados com margem de lucro muito baixa ou até negativa, quando os sócios chegavam a pagar para trabalhar. Por outro lado, era necessário o fechamento de contratos, para qualificar a equipe de trabalho, para ganhar mais experiência e domínio técnico. Além disso, a experiência de interação com empresas de maior porte e mais organizadas oportunizava aprendizagem de processos formais, que contribuía para muitas melhorias de processos da própria empresa, pois, via de regra, por causa de uma série de erros de planejamento de produção, costumavam trabalhar até em fins de semana e durante as madrugadas.

As exigências e as formalidades de entrega e validação dos produtos pelas agências de maior porte obrigaram a empresa a implementar novos processos e a buscar otimização e maior clareza nas etapas de produção e nos papéis desempenhados pelos membros da equipe.

O sucesso na área comercial refletia-se no ingresso constante de recursos, aliviando a pressão sobre o fluxo de caixa. No entanto, na maior parte dos projetos, os prazos eram muito curtos e os recursos não correspondiam aos custos de produção, que alcançavam o valor mensal de R\$ 11.000,00. Desta forma, os maiores ganhos, no final do segundo ano e no terceiro ano, ainda centravam-se na experiência dos sócios relativa ao atendimento à área de jogos e produção. Alguns dos profissionais que trabalhavam na Ilinx Entretenimentos destacaram-se positivamente e conquistaram a confiança dos sócios, outros, porém, foram desligados ou desligaram-se por motivos externos.

Durante os três primeiros anos de funcionamento da empresa, foram produzidas algumas dezenas de jogos, mas todos foram vendidos como serviço, sem registro da propriedade intelectual, obrigando os empreendedores a voltar a investir em prospecção assim que era finalizado o contrato. $\mathrm{O}$ desgaste gerado por este modelo de negócios repercutia, principalmente, no tempo de trabalho dos sócios, que era compartilhado entre universidade e empresa. Apesar disso, os dois empreendedores sentiam que estavam no caminho correto e que a construção do portfólio estava sendo bem assentada.

REAd | Porto Alegre - Edição 84 - N 2 - Maio / Agosto 2016 - p. 543 - 571 


\section{Dusan Schreiber, Cristiano Max Pereira Pinheiro, Marsal Ávila Alves Branco, Cláudia Simone Antonello \& Deise Land}

O único aspecto que ainda permanecia aquém do desejado e com potencial de risco era a rentabilidade do negócio. Ela estava negativa, o que corroía a capacidade financeira da empresa para investir no segmento que os dois sócios pretendiam atingir desde o início da operação - os jogos próprios. Para fazê-los, teriam que destinar para o projeto recursos humanos que eram caros. Desta forma, a empresa usava apenas os tempos 'mornos', entre projetos de jogos encomendados, para se dedicar à produção de títulos próprios.

Assim foi criado o projeto Zumbis. Nos tempos livres, os dois empreendedores começaram a prototipar (em código e em modelo de negócios) a criação desse jogo, que se propunha a configurar uma franquia de jogos para mobile. Em paralelo, com o objetivo de desvendar o funcionamento do sistema comercial de jogos, os dois sócios se entrosaram com os players do segmento, em âmbito estadual e nacional, também aproveitando, para tanto, a visibilidade conquistada no meio acadêmico. Engajaram-se, ativamente, com profissionais, associações, empresas e setores do governo (estadual e federal) ligados a jogos, abrindo espaços para si e para a empresa.

No início do ano 2010, os sócios resolveram investir na contratação de mais pessoas, de alta qualidade técnica, com salários diferenciados. Desta forma, o faturamento no ano mais do que dobrou, passando a $\mathrm{R} \$ 125.000,00$. Contudo, devido ao aumento de pessoal, ao pagamento de custos, ao financiamento de máquinas, às dívidas dos anos anteriores, a empresa ainda continuava em crise. Nesse momento, a crise não era muito grave porque os sócios conseguiam dar conta dos salários e dos custos através da tomada de empréstimos pessoais.

No início de 2011, com uma equipe madura, com um bom portfólio e acreditando mais no negócio, houve a tomada de novos empréstimos para manter a empresa funcionando durante o prazo mais longo possível. O aumento do faturamento facultou o crescimento do endividamento junto aos agentes financeiros. Entretanto, as perspectivas de viabilizar a empresa permaneciam, principalmente por haver a percepção de que o mercado publicitário não comprava como deveria, não pagava o que deveria, situação que impedia estabelecer um caixa suficiente para realizar o projeto original - jogos próprios.

Ao final de 2011, a empresa estava novamente em crise financeira, com acúmulo de todos os déficits dos anos anteriores e sem perspectiva de tomada de novos empréstimos, quer como pessoa jurídica, quer em nome da pessoa física dos sócios. O principal motivo de tal quadro prendia-se ao descompasso entre o faturamento gerado e os custos de produção. Apesar de o faturamento anual ter sido novamente duplicado, passando a $\mathrm{R} \$ 250.000,00$, os 


\section{NO JOGO DO MERCADO: O CASO DE UMA STARTUP GAÚCHA}

custos cresciam em dissonância com as entradas. Os sócios decidiram que encerrariam a operação em janeiro de 2012, data do último pagamento de trabalho que estavam realizando, quando algo inesperado aconteceu.

\section{INGRESSO DO NOVO SÓCIO E MUDANÇA DE FOCO}

Nesse período, Cristiano e Marsal conheceram uma pessoa com interesse em investir na empresa. Tratava-se de um engenheiro, empresário do setor de polímeros, que procurou o curso de jogos digitais da Universidade Feevale, pois estava querendo investir em um negócio de tecnologia e haviam recomendado a ele que entrasse em contato com a Universidade Feevale por ela ter um curso de jogos. Esse empresário havia vendido sua empresa para uma multinacional e estava vivendo de rendimentos, pois estava impedido, por determinado tempo, de abrir outra empresa no ramo de polímeros. O investidor, Márcio, foi atendido pelo Marsal na Universidade. Após este contato, ele compartilhou com Cristiano a ideia de oferecer a Márcio sociedade na empresa.

A situação real da empresa foi apresentada a Márcio,, seguindo-se a oferta para que ele tivesse participação de $33 \%$ na sociedade. O ponto mais importante, além do aporte de capital, era a experiência administrativa de Márcio, considerada pelos dois empreendedores muito propícia para o momento pelo qual a empresa estava passando. A participação do novo sócio em $33 \%$ da sociedade facultaria quitar tanto as dívidas contraídas em nome da pessoa jurídica como as tomadas em nome de pessoas físicas.

A ideia era zerar as contas e ter um caixa que assegurasse uma sobrevida de, aproximadamente, três meses, para geração de mais negócios. Com a experiência de Márcio (novo sócio), seria possível administrar melhor os recursos e ter um horizonte mais saudável. Além disso, Márcio havia colocado à disposição da empresa suas influências em setores corporativos e de marketing, o que trazia o respaldo necessário para o ingresso no mercado. Dentro da avaliação do ingresso de Márcio na sociedade, foi também considerado o fato de ele estar disposto a trabalhar na empresa, contribuindo ativamente para a gestão do negócio.

O ingresso do novo sócio e a capitalização empresarial renovaram as esperanças tanto de Cristiano como de Marsal, quanto ao futuro, respaldando sua decisão de contratar dois colaboradores seniors, com salários mais altos que a maioria, a fim de coordenarem a equipe, lhe darem mais qualidade e melhorarem seu clima. Os custos mensais já chegavam à casa de $\mathrm{R} \$ 30.000,00$, o que exigia mudanças na atuação comercial da empresa. O primeiro passo,

REAd | Porto Alegre - Edição 84 - N 2 - Maio / Agosto 2016 - p. 543 - 571 


\section{Dusan Schreiber, Cristiano Max Pereira Pinheiro, Marsal Ávila Alves Branco, Cláudia Simone Antonello \& Deise Land}

com o ingresso de Márcio , foi a redefinição da atuação e das responsabilidades de cada um dos sócios na empresa. Cristiano ficou responsável pela produção; Marsal, por relacionamento e projetos; Márcio pela administração. Além disso, Marsal e Márcio iriam assumir a prospecção, coordenando o atendimento às agências de publicidade, segmento prioritário em termos de geração de receita operacional.

No entanto, intenções e proposições não se concretizaram da maneira idealizada. Em pouco tempo, os empreendedores constataram que o novo sócio que se recusava entender as especificidades do negócio, argumentando que não era 'técnico' no assunto. Isso dificultava enormemente as possibilidades de vendas, normalmente feitas em dupla com Marsal. $\mathrm{Na}$ medida em que Márcio não conseguiu entregar o que ele havia prometido, por ocasião do ingresso na sociedade, em termos de alavancagem comercial, houve a resolução de incitar algo que exigisse menos dele no processo do negócio, que correspondia à retomada do projeto original da empresa - a produção de jogos próprios.

Devido ao aporte de capital advindo do ingresso do Márcio na sociedade, o horizonte financeiro era, aproximadamente, de dois meses. Dada à frustração de trabalhar com jogos sob demanda para empresas e à excitação de produzir algo com propriedade intelectual (já existiam os rascunhos e protótipos do jogo de zombies) a perspectiva de tornar a empresa financeiramente rentável começava a parecer razoável. Poucos meses depois, todos os esforços da equipe estavam voltados exclusivamente para a produção do Jogo World League Zombies, para plataformas mobiles (um jogo de corrida, no estilo olimpíadas, com personagens Zombies, fazendo alusão as famosas Zombie Walks que acontecem em países como Inglaterra, Estados Unidos, Brasil, entre outros), que comprometeu, aproximadamente, recursos da ordem de R \$ 100.000,00. Esse processo de decisão culminou com a redefinição de estratégias da empresa, de sua missão, de seus valores e a reflexão sobre a empresa, o papel dos sócios, os processos internos, o relacionamento com o mercado. As decisões foram tomadas em reuniões semanais, com apoio de uma consultoria obtida através de parceria com outra empresa.

Nesse processo, foi definido o foco em propriedade intelectual (jogos próprios). A aposta, no entanto, era arriscada: o jogo têm que dar certo ou o dinheiro acaba. Por essa razão, toda a equipe foi mobilizada para finalizar a produção e foi intensificada a busca por recursos de investidores e publishers. Do ponto de vista da produção, a empresa contava com uma equipe competente, porém cara (para os padrões do mercado de jogos), a qual possibilitou alcançar nível internacional, tanto na qualidade estética como na programação. Nesse período,

REAd | Porto Alegre - Edição 84 - Nº 2 - Maio / Agosto 2016 - p. 543 - 571 


\section{NO JOGO DO MERCADO: O CASO DE UMA STARTUP GAÚCHA}

a empresa participou de diversas seleções de projetos. Ela ficou entre os 10 melhores projetos (entre mil) do concurso "Anjos do Brasil", recebendo a oportunidade de apresentar o plano de negócios para alguns dos maiores investidores anjos e fundos de investimento do país. Além disso, foram estabelecidos promissores contatos com outros grupos de investidores qualificados. Os empreendedores tiveram a impressão de que todos os participantes ficavam encantados, compartilhando a visão de que tinham, de fato, algo grande nas mãos. No entanto, esta percepção não se traduzia em negócios. Ao final de seis meses de produção, o dinheiro não entrou.

Todo o período da nova sociedade foi marcado por um delicado equilíbrio entre os sócios, especialmente nas relações entre Márcio e Cristiano, cujas diferenças ocorriam em dois níveis: visão de como desenvolver o negócio e forma de se comunicar. Quanto ao primeiro aspecto, Márcio pressionava por corte de custos, resultados e profissionalização, destacando-se a pressão para definir o papel e a atuação da esposa de Cristiano na empresa.

Quanto ao segundo nível, Márcio adotava uma política de 'falar a verdade doa a quem doer', o que tornava o ambiente desnecessariamente bastante áspero, conforme a percepção de Cristiano e de Marsal, pois, na maioria das vezes tratava-se de assuntos que poderiam ser considerados de forma mais branda ou política. Essa característica acabou contribuindo para suscitar desconforto na convivência entre os sócios, assumindo, por vezes, uma dimensão muito pessoal, especialmente para Cristiano. Marsal, na maioria das vezes, assumiu a responsabilidade de mediar o conflito entre Márcio e Cristiano, procurando encontrar uma pauta comum ou a convergência das opiniões dos dois, as quais, quase sempre, eram antagônicas.

Então, na questão mais delicada, Marsal manifestou-se a favor da saída de Gil (esposa de Cris), por entender que, de fato, sua presença não ajudava a melhorar os processos nem a profissionalizar a empresa, por misturar, em excesso, questões profissionais e pessoais. Para além dessa questão, o aspecto financeiro tornou-se muito difícil, havendo um custo fixo muito grande que apenas Márcio tinha condições financeiras, pessoais para sustentar. A cada novo mês, era preciso buscar mais dinheiro, ampliando o grau de endividamento dos dois sócios originais. Era setembro de 2012, a empresa recém tinha fechado a operação com a Sicredi, no valor de R \$ 30.000,00, e assinado a operação com o Bradesco, no montante de R \$ 60.000,00. Essas tomadas de recursos, assim como a terceira, de R $\$ 120.000,00$, que estava sendo planejada, a uma taxa reduzida, junto à Caixa Econômica Federal, só poderiam ser realizadas com o aval do Márcio, na qualidade de fiador. No entanto, justamente nesse momento,

REAd | Porto Alegre - Edição 84 - N 2 - Maio / Agosto 2016 - p. 543 - 571 


\section{Dusan Schreiber, Cristiano Max Pereira Pinheiro, Marsal Ávila Alves Branco, Cláudia Simone Antonello \& Deise Land}

Márcio, alegando estresse excessivo, falta de afinidade com o negócio e perda de confiança na viabilidade do negócio, desligou-se da sociedade. Sua proposta era retornar os percentuais dos outros sócios da empresa sem nenhum valor em troca, ou seja, ele queria apenas sair.

\section{DECLÍNIO E ENCERRAMENTO DA ATIVIDADE}

Quando Márcio saiu, a empresa tinha recursos financeiros para bancar o montante de despesas fixas pelo período de, aproximadamente, 45 dias. Cristiano e Marsal tinham esperança, como durante todo o percurso da empresa, de que algum trabalho, alguém ou uma publisher (com a qual vinham em tratativas para o lançamento do jogo) pudesse aportar algum recurso. Quando estavam disponíveis recursos financeiros para apenas 30 dias, a empresa participou da feira de negócios SBGames 2012, em Brasília, os dois empreendedores conseguiram fazer vários contatos promissores, que poderiam se traduzir em negócios e, assim, salvar a empresa. Destes contatos, a perspectiva mais real era a da parceria com a Publisher Móvile que acenava com a possibilidade de aporte de alguns recursos. Considerando a história pregressa dos dois e da empresa, a superação de diversos momento críticos, ao longo de cinco anos, tanto Cristiano como Marsal tinham esperança de que dificuldades pelas quais passavam também seriam superadas.

A saída de Márcio marcou o início da última fase da operação, que culminou com o fechamento da empresa, justamente quando foi, finalmente, firmado um contrato de parceria com um publisher disposto a publicar o jogo, o qual inclusive alocou recursos financeiros para divulgação. $\mathrm{O}$ objetivo desta parceria era lançar o jogo e aprender o que ainda faltava à empresa referente ao comportamento do mercado de jogos, ou seja, acompanhar, em âmbito global, a resposta dos gamers em relação ao jogo e levantar suas métricas de uso. Até então, havia sido realizado apenas o lançamento piloto, na Inglaterra, o qual redundou em fracasso de vendas. Quando era pago, não havia volume de vendas. Quando era gratuito, era perdida a capacidade de retenção de usuários.

O jogo conseguiu visibilidade inicial, pois, de fato, apresentava uma qualidade estética acima da média, o que the facultava a abertura de algumas portas. No entanto, os resultados do lançamento piloto, em território britânico, sinalizaram que o jogo, no qual empresa apostara e para o qual alocara recursos financeiros e humanos significativos, não era um produto vencedor. Era bonito, bem produzido e sem erros técnicos, mas não tinha a chamada 'jogabilidade vencedora', que é o caráter divertido e desafiador que caracteriza os produtos de 


\section{NO JOGO DO MERCADO: O CASO DE UMA STARTUP GAÚCHA}

maior sucesso da área. Com os pequenos aportes em comunicação operados pelo publisher, os números ficaram claros: os dólares investidos em comunicação (fazendo o jogo ser falado e conhecido) não retornavam um valor significativo.

$\mathrm{O}$ aporte de recursos, no volume mínimo necessário, não ocorreu. O fracasso, mais caro do que poderiam prever, obrigou os empreendedores a encerrar a operação. A mais difícil de todas as decisões consistiu em falar aos colaboradores acerca do fechamento da operação e comunicar o desligamento de todos. O encerramento das atividades implicava assumir diversas dívidas adicionais, além das financeiras, contraídas junto a vários agentes financeiros. Haveria necessidade de providenciar recursos para pagamento das demissões, de impostos atrasados, da entrega do imóvel, entre outros compromissos, cujo valor totalizava, apenas na pessoa jurídica, aproximadamente $\mathrm{R} \$ 250.000,00$, excluindo-se as dívidas pessoais contraídas para repassar os recursos à empresa,.

Não havia muitas alternativas. A orientação recebida, tanto do contador como de um advogado contratado para assessorá-los, foi de que deveriam priorizar o pagamento das dívidas trabalhistas, pois as demais poderiam ser negociadas em termos de prazos para pagamento. Esta orientação foi seguida à risca. Os dois empreendedores cumpriram com as obrigações trabalhistas, previdenciárias e fiscais e depois agendaram reuniões com os bancos para negociar prazos de pagamento dos empréstimos contraídos. Naquele momento, os avisos do SPC (Serviço de Proteção ao Crédito) já haviam chegado tanto para Cristiano e Marsal, como para Márcio que, mesmo tendo se desligado da sociedade, era fiador das dívidas, estando, portanto, implicado na dívida.

Apesar do encerramento da operação, Marsal, do ponto de vista pessoal, considerou a experiência rica e válida, sob a perspectiva de aprendizagem adquirida em relação ao segmento e à gestão de uma empresa. Esta experiência propiciou aos sócios refletirem e os levou a repensar o processo que os induziu a lançar, no mercado, um produto falho, facultando a identificação de erros.

Cristiano também valorizou o aprendizado sobre sistema de produção, marketing, comercialização, negociações com a cadeia produtiva, gestão administrativa e financeira, propriedade intelectual, ações jurídicas e contábeis. Considerou a experiência um tipo de graduação prática de gestão de negócios. Ele acredita que, em futuro próximo, será possível assumir um novo desafio de empreendimento no setor de jogos,.

\section{NOTAS DE ENSINO}

REAd | Porto Alegre - Edição 84 - N 2 - Maio / Agosto 2016 - p. 543 - 571 


\section{Dusan Schreiber, Cristiano Max Pereira Pinheiro, Marsal Ávila Alves Branco, Cláudia} Simone Antonello \& Deise Land

\section{1 Objetivos Educacionais do Caso}

O caso permite abordar, analisar e discutir elementos relativos principalmente a: empreendedorismo em atividades relacionadas à indústria criativa; concepção e operacionalização de marketing de produtos da indústria criativa; desafios de organizar o trabalho de pessoas no ambiente organizacional, especialmente nos primeiros anos da operação. Apresenta também evidências da relevância da reflexão estratégica como elemento estruturante da operação empresarial.

\subsection{Fontes de Obtenção dos Dados}

Os dados para a elaboração do caso foram obtidos por meio de narrativa dos empreendedores e de dados secundários, tais como relatórios internos.

\subsection{Utilização Recomendada}

Como os pontos-chave de análise do caso estão baseados na identificação de elementos do processo de planejamento e de implementação de uma startup, voltada para concepção, elaboração e comercialização de jogos digitais. Acredita-se que o caso possa ser utilizado em disciplinas de graduação e pós-graduação que discutam: indústria criativa, empreendedorismo, marketing, estratégia organizacional e temas correlatos.

\subsection{Situação-problema}

Empresa inicia a produção de jogos digitais e encontra dificuldades neste processo, apesar da notória competência técnica dos empreendedores.

\section{SUGESTÕES DE QUESTÕES PARA DISCUSSÃO}

\subsection{Avaliação da Experiência Empreendedora em Startups de base tecnológica}

. Apresentar, analisar e discutir a concepção do projeto empresarial.

- Avaliar o processo de identificação de oportunidade comercial e os desafios, por se tratar de REAd | Porto Alegre - Edição 84 - Nº 2 - Maio / Agosto 2016 - p. 543 - 571 


\section{NO JOGO DO MERCADO: O CASO DE UMA STARTUP GAÚCHA}

um dos segmentos classificados como indústria criativa.

. Analisar as especificidades do processo de concepção, elaboração e distribuição de jogos digitais, segmento competitivo e global.

- Evidenciar os aspectos financeiros que envolvem todo o processo de concepção, planejamento, elaboração de jogos digitais, bem como sua distribuição, com impacto relevante sobre cash flow.

. Avaliar o processo decisório em termos de alocação de recursos e formação de parcerias comerciais, bem como sua importância para o sucesso do empreendimento.

. Identificar e sugerir ações que os dois sócios deveriam desenvolver numa nova tentativa empreendedora.

- Analisar as questões de conteúdo que envolvem as relações e o contrato informal que se estabelece entre os sócios e a política de convivência frente aos problemas.

\subsection{Atitudes a Estimular}

. Compreensão do processo de empreendedorismo de base tecnológica, especialmente em planejamento, desenvolvimento e comercialização de jogos digitais, em toda a sua extensão, desde a concepção até a concretização, assim como suas implicações, procedimentos legais e financeiras.

- Compreensão de como estrategistas e empreendedores aprendem por suas práticas de trabalho em seu cotidiano.

\section{ANÁLISE DO CASO}

\subsection{Tema: Avaliação da Experiência Empreendedora em Jogos Digitais}

Cristiano e Marsal encontravam-se, aparentemente, em posição privilegiada, em relação a muitos empreendedores brasileiros. A formação em nível superior e a experiência profissional em suas áreas específicas de atuação, juntamente com a disponibilidade de recursos financeiros para investir, representam, a priori, vantagem significativa para o empreendedor, além de maior probabilidade de sucesso na implantação do projeto empresarial. De forma racional, com cautela e precaução, ambos optaram por permanecer em seus empregos, adotando o modelo de gestão semipresencial. Isto lhes permitiu certa tranquilidade, pois continuavam tendo uma receita fixa, advinda de seus salários, enquanto REAd | Porto Alegre - Edição 84 - N 2 - Maio / Agosto 2016 - p. 543 - 571 


\section{Dusan Schreiber, Cristiano Max Pereira Pinheiro, Marsal Ávila Alves Branco, Cláudia Simone Antonello \& Deise Land}

estruturavam o negócio, processo que, nos primeiros meses, apresenta, tradicionalmente, resultados financeiros negativos.

No entanto, este tipo de cautela, na percepção de vários pesquisadores, pode evidenciar falta de confiança na capacidade empreendedora, como também insegurança em relação à oportunidade prospectada (Drucker, 2002; Global Entrepreneurship Monitor [GEM], 2012). Na questão de planejamento do negócio e da forma de implantação do projeto, os empreendedores demonstraram muita competência, constituindo-se estes dois pontos nos mais fortes na condução do processo de implantação da empresa, como considerado por Britto e Wever (2003). A capacidade relacional com foco em estabelecimento de redes de contato também é percebida como relevante, quer na literatura revisada sobre empreendedorismo (Britto \& Wever, 2003; Drucker, 2002), quer em pesquisas de natureza empírica (GEM, 2012). Foi nela que os empreendedores se apoiaram na estruturação tanto da parte administrativa e de apoio como da operação em si, através de representantes e distribuidores e de agência de publicidade e propaganda.

As decisões relativas à precificação inicial dos trabalhos realizados também são relevantes para o empreendedor, segundo Amorim (1998), Drucker (2002), Britto e Wever (2003), Maculan (2003) e Filardi e Soares (2004). Este quesito foi atendido satisfatoriamente pelos empreendedores, respaldado em experiência anterior que eles possuíam. Nas notas a seguir, destacam-se alguns pontos que fundamentam as bases conceituais abordadas no caso.

\subsection{Análise das atividades em startups}

A sociedade do século XXI é conhecida como a sociedade do conhecimento. A economia criativa é destacada por muitos como a revolução do sistema social, econômico e cultural, por meio do acesso à educação. Motivadas pela globalização e pelas evoluções tecnológicas, as alterações repercutem, frente a incertezas do mercado, em novas formas de gestão de recursos (SANTOS, 2005).

Com o advento de computadores móveis, tablets e smartphones, definidos como “[...] dispositivos de acesso a sistemas de informações via internet, equipados com sistemas operacionais sofisticados, e os aplicativos ganham mais importância” - Revista Exame, (2014, p. 40), potencializados pela rapidez com que novas formas e novos métodos de executar atividades corriqueiras são desenvolvidos e introduzidos no mercado. Esses novos modelos de negócio podem ser considerados a evolução do empreendedorismo: as startups, 


\section{NO JOGO DO MERCADO: O CASO DE UMA STARTUP GAÚCHA}

empresas recém-criadas ou ainda em fase inicial de estruturação, fundamentadas na oferta de um produto promissor ou em um modelo de negócio repetível escalável, porém de alto risco (SILVA et al., 2013).

Modelo de negócio repetível pode ser definido como aquele que tem a capacidade de entregar o mesmo produto ou serviço novamente, sem precisar desenvolver novas customizações ou alterações individuais ou ter que criar novas estruturas. Ser escalável representa ter a capacidade de entregar uma ou várias unidades do produto ou serviço, independente da demanda, sem que isso influencie o modelo de negócio, podendo oferecer uma margem de lucro cada vez maior, propiciando a geração e o acúmulo de riquezas, a custos cada vez menores (GITAHY, 2010).

A crise econômica mundial do ano de 2008 impulsionou o surgimento das startups, como alternativa ao trabalho convencional e sob a perspectiva da melhor qualidade de vida que o negócio próprio pode proporcionar a seu fundador (THE ECONOMIST, 2014). Na visão de Gaspar (2010), os empresários, especialmente os mais jovens, consideram o empreendedorismo de startup uma interseção entre ciência e arte, por meio dos padrões de repetição do sucesso e do fracasso já conquistados por outros empreendedores de startups, podendo servir de exemplo para novos empreendedores, bem como aumentar exponencialmente as chances de inovar através da socialização e do conhecimento. Contudo, apesar da janela de oportunidades por meio deste novo formato terem sido divulgadas com mais intensidade somente nos últimos dois ou três anos, o número de novos empreendedores tecnológicos alcançou o ponto de massa crítica (MARMER et. al., 2012).

No Brasil, os índices de empreendedorismo tecnológico ou startup de base tecnológica têm sido cada vez maiores, justificados pela redução dos custos de criação e inicialização, por serem facilmente monetizáveis, com baixo custo de manutenção e distribuição. Representam expectativas de geração lucros de forma exponencial. Startups de base tecnológica são organizações a fim de criar e desenvolver soluções para necessidades específicas de um conjunto de pessoas, com foco em nichos de mercado ainda não atendidos ou atendidos inadequadamente. Na maioria das vezes, as startups de base tecnológica iniciam suas atividades com protótipo ou produto mínimo viável, a fim de validar sua ideia e atrair aportes milionários através de investidores (MARMER et al., 2012; SILVA et al., 2013; HARTMANN， 2013; XAVIER; CANCELLIER，2008; ADMINISTRADORES， 2014; ABSTARTUP, 2014).

Para a Secretaria da Economia Criativa (2011), startups são empresas nascentes, que REAd | Porto Alegre - Edição 84 - N 2 - Maio / Agosto 2016 - p. 543 - 571 


\section{Dusan Schreiber, Cristiano Max Pereira Pinheiro, Marsal Ávila Alves Branco, Cláudia Simone Antonello \& Deise Land}

querem validar, junto ao mercado, sua ideia inovadora de produto ou modelo de negócio inovador. Neste estágio inicial, executam algumas atividades básicas, bem como cogitar algumas atividades estratégicas, a fim de se posicionarem no mercado, executar atividades operacionais com foco na construção de um protótipo, ajustando a produção à comercialização do produto em escala comercial, com o propósito de configurar a operação dentro do modelo inicial, definido como lean startup.

Para a Marmer (2012), as atividades de desenvolvimento de clientes e de novos parceiros, assim como a metodologia lean startup, são adotadas como ferramentas de gestão, de maneira generalizada, para este modelo de negócio. Entretanto, os fundadores correm o risco de diluir seu foco ou escolher um direcionamento inadequado. O fato é que se, atualmente, com maior frequência do que se fazia no passado, as startups utilizam-se de feedbacks com dados e informações quantitativas e qualitativas, falta-lhes ainda a capacidade de interpretação para tomar a melhor decisão. Isso acontece porque são, frequentemente, bombardeadas com conselhos que podem parecer contraditórios, o que pode ter efeito paralisante.

Xavier e Cancellier (2008) ressaltam uma característica peculiar deste novo modelo de fazer negócios. Indiferentemente do porte, empresas startups tendem a descrever, no plano de negócio, a análise de mercado, e do ambiente competitivo, detalhadamente, para, então, a partir dessas informações, traçar o plano estratégico para seu negócio. Como em empresas de pequeno porte, startups, ocorre a centralização da tomada de decisão na figura do empreendedor, as decisões podem assumir um viés individual, com possibilidades negativas, quando o plano de negócios for submetido aos investidores de capital de risco para análise, visando à tomada de recursos no mercado. Nesse caso, os investidores podem exigir mudanças relevantes no projeto, alterando, de forma significativa, a estrutura prevista.

Na visão de Xavier e Cancellier (2008), a influência exercida pelo investidor acontece com maior intensidade devido às incertezas de mercado e à inexistência de rotinas e práticas que trariam maior credibilidade às informações coletadas. Na análise estruturada para a tomada de decisão, a vulnerabilidade torna-se mais evidente, pois as startups, por serem novas, normalmente não contam com estruturas de assessoramento nem estão associadas a entidades de classe, o que lhes proporcionaria suporte no monitoramento e acesso a informações.

A inexistência de rotinas administrativas tradicionais em startups é destacada por Silva et al. (2013) e justificada pelo fato de serem empresas nascentes, sem muita movimentação 


\section{NO JOGO DO MERCADO: O CASO DE UMA STARTUP GAÚCHA}

administrativa, bem como pela percepção equivocada dos empreendedores, que tentam suprimir a burocracia praticada em empresas já consolidadas, por considerar que as práticas gerenciais tradicionais engessariam a empresa, impedindo a rápida resposta que o mercado globalizado exige, além de torná-las pouco criativas.

No Quadro 1, destacam-se algumas características do modelo startup exposto por Silva et al. (2013).

Quadro 1 - Característica de uma startup de base tecnológica.

\begin{tabular}{|c|c|}
\hline $\begin{array}{l}\text { Modelo de negócio replicável e escalável. Não se preocupam em } \\
\text { descontinuar seu produto/serviço precocemente. }\end{array}$ & $\begin{array}{l}\text { Isso minimiza o custo unitário de } \\
\text { produção e facilita gerar o máximo de } \\
\text { receita com o mínimo de custo, } \\
\text { indiferente da demanda. }\end{array}$ \\
\hline Nicho de mercado específico & $\begin{array}{l}\text { Focada em determinada solução para } \\
\text { um problema. Geralmente, a solução } \\
\text { surge a partir de um problema } \\
\text { identificado por um dos sócios da } \\
\text { startup. }\end{array}$ \\
\hline Entre o mapa e o terreno, fica com o terreno. & $\begin{array}{l}\text { Diferentemente de negócios } \\
\text { tradicionais, startups desenvolvem e } \\
\text { entregam rapidamente a solução para o } \\
\text { mercado. }\end{array}$ \\
\hline Validação do produto de baixo custo & $\begin{array}{l}\text { Rejeita as custosas pesquisas de } \\
\text { mercado para comprovar suas ideias, a } \\
\text { internet e outras ferramentas criativas } \\
\text { é que lhe dão insights. A validação do } \\
\text { produto ou serviço geralmente } \\
\text { acontece depois de sua apresentação ao } \\
\text { mercado, o que reafirma a a } \\
\text { instabilidade de o negócio ter sucesso } \\
\text { ou não. }\end{array}$ \\
\hline Seu empreendedor é desapegado. & $\begin{array}{l}\text { Empreendedor de startup empreende } \\
\text { em série e, geralmente, vende sua } \\
\text { empresa. }\end{array}$ \\
\hline $\begin{array}{l}\text { Não acredita no valor de uma ideia em si, mas na execução. Libera a } \\
\text { equipe para inovar. }\end{array}$ & $\begin{array}{l}\text { Entregam a solução ao mercado, } \\
\text { mesmo que esta não esteja madura. O } \\
\text { importante para estes empreendedores } \\
\text { é serem os primeiros, pois, em sua } \\
\text { visão, isso garante uma boa parcela de } \\
\text { mercado no nicho escolhido. }\end{array}$ \\
\hline $\begin{array}{l}\text { Não possui hierarquia de fato. Colabora até com concorrentes e } \\
\text { desconhecidos. }\end{array}$ & $\begin{array}{l}\text { O leiaute dos escritórios deixa tudo } \\
\text { plano, ou seja, presidentes, sócios e } \\
\text { funcionários trabalham no mesmo } \\
\text { espaço, o que facilita a comunicação } \\
\text { constante. A melhor solução pode vir } \\
\text { de qualquer membro da equipe, o que } \\
\text { aumenta a confiança. A troca de ideias } \\
\text { e serviços entre colegas de trabalho, } \\
\text { concorrentes e até desconhecidos são } \\
\text { frequentes no ambiente startup. }\end{array}$ \\
\hline
\end{tabular}

Fonte: adaptado pelos autores de Silva et al. (2013, p. 8).

A maioria dos atores econômicos, públicos ou privados, deposita grandes expectativas

REAd | Porto Alegre - Edição 84 - N 2 - Maio / Agosto 2016 - p. 543 - 571 


\section{Dusan Schreiber, Cristiano Max Pereira Pinheiro, Marsal Ávila Alves Branco, Cláudia Simone Antonello \& Deise Land}

neste novo modelo de negócios, por considerarem as startups de base tecnológica o grande fenômeno do empreendedorismo criativo do século XXI. Elas representam uma alternativa para a solução da crise econômico-financeira, bem como uma nova fonte de recursos e possibilidades de diversificar a economia.

\subsection{Caracterizando a praxis empreendedora}

O empreendedor é, frequentemente, apresentado como herói que assume riscos para transformar radicalmente o modo de produzir ou de abrir novos mercados. Há no entanto, uma imagem diferente. $\mathrm{O}$ empreendedor é também um indivíduo que tem competências para se inserir em redes, gerenciar interações, vigiar o ambiente externo, identificar oportunidades (GUIMARÃES; AZAMBUJA, 2010). Ele vai se inserindo no ambiente econômico em mutação, encontrando brechas e nichos e criando seu próprio emprego. Dessa maneira, ele participa do processo de difusão de novas tecnologias mediante a oferta de bens e serviços originais. Ele já não é mais um ator econômico isolado, mas ao contrário, trabalha em cooperação com outras empresas, de grande ou pequeno porte (MACULAN, 2003, p. 314; GUIMARÃES; AZAMBUJA, 2010).

Esta realidade percebe-se especialmente no segmento de negócios de base tecnológica, como é o caso de empresas que produzem jogos digitais. Guimarães e Azambuja (2010) constataram que os negócios caracterizados como high-tech facultam a convergência de projetos com base no alinhamento de interesses e expectativas de empreendedores, de cunho tanto pessoal como profissional. Martens, Freitas e Andres (2011) corroboram a referida constatação, ao afirmar que os empreendedores de negócios do setor de software manifestam uma orientação empreendedora peculiar e específica, o que sugere que o tipo de atividade influencia a forma de como o empreendedor se posiciona frente às oportunidades e as escolhas de estratégias adotadas.

Segundo autores que abordam o empreendedorismo, como Amorim (1998), Drucker (2002), Britto e Wever (2003), Maculan (2003), Filardi e Soares (2004), Guimarães e Azambuja (2010) e Martens, Freitas e Andres (2011), o empreendedorismo é fundamental para o desenvolvimento econômico e social. Para Drucker (2002) o tema do empreendedorismo pode ser compreendido a partir de duas vertentes: (i) geração de novos negócios ou criação de uma empresa; (ii) expansão de uma empresa ou de um negócio já existente. Nas duas situações percebe-se a essência do espírito empreendedor, ou seja, a busca e a exploração de novas oportunidades no ambiente.

REAd | Porto Alegre - Edição 84 - Nº 2 - Maio / Agosto 2016 - p. 543 - 571 


\section{NO JOGO DO MERCADO: O CASO DE UMA STARTUP GAÚCHA}

Com base na vertente teórica analisada, Cristiano e Marsal denotam as características que evidenciam o empreendedorismo retratado na literatura: identificação de uma oportunidade no ambiente, de um possível negócio com potencial para criar redes de relacionamento e geração de oportunidades de emprego. Percebe-se a relevância da parceria e do interesse comum entre os sócios, formando a base para a concepção do negócio em consonância com os resultados do relatório da GEM (2012), no qual foi evidenciada a taxa mais elevada de sucesso entre as empresas com sócios do que entre as empresas com empreendedor individual.

A pesquisa da Global Entrepreneurship Monitor do ano 2012 apresenta outras contribuições relevantes para o estudo da origem do comportamento empreendedor, por exemplo, a importância do aspecto motivacional. Nesta perspectiva, identifica as duas forças propulsoras mais relevantes: a oportunidade e a necessidade. O empreendimento de oportunidade surge quando ocorre o investimento em um novo negócio, a fim de aproveitar uma oportunidade percebida no mercado. No entanto, o empreendimento percebido como de necessidade decorre da criação de negócios na busca de trabalho e ocupação, caracterizandose por ser a melhor opção disponível em determinado momento.

Segundo o relatório da GEM (2012), o Brasil se situa entre os países de renda per capita média e, como os demais países desta categoria, as empresas iniciadas com base em oportunidades percebidas no mercado representam um percentual inferior a $50 \%$ do total dos empreendimentos anualmente iniciados. No entanto, este não foi o caso de Cristiano e de Marsal que iniciaram suas atividades com base na clara percepção de oportunidade de mercado, em um segmento do qual ambos já possuíam conhecimento prévio, importante para a obtenção de sucesso, conforme pensam Drucker (2002), Filardi e Soares (2004) e Maculan (2003) e Marçal et al (2012).

Em outro momento, percebe-se igualmente o comportamento empreendedor, quando os dois sócios se deparam com a mudança das condições originalmente previstas para o desenvolvimento do negócio de produção de jogos digitais, evidenciando iniciativa, flexibilidade e capacidade de se adaptar a novas situações, que são as características empreendedoras, conforme Amorim (1998), Guimarães e Azambuja (2010), Martens, Freitas e Andres (2011) e Marçal et al (2012). Drucker (2002) ressalta como a característica do empreendedor a busca pela inovação, seja por meio de novo produto, seja pelo processo de organização de recursos de uma maneira nova.

Alinhada com esta abordagem do comportamento do consumidor, percebe-se que

REAd | Porto Alegre - Edição 84 - N 2 - Maio / Agosto 2016 - p. 543 - 571 


\section{Dusan Schreiber, Cristiano Max Pereira Pinheiro, Marsal Ávila Alves Branco, Cláudia Simone Antonello \& Deise Land}

tanto Cristiano como Marsal inovaram (SCHUMPETER, 1982) ao optar por um produto de nicho específico e organizar um sistema de comercialização condizente à proposta de capilaridade em centros consumidores desta categoria de produtos. $\mathrm{O}$ tecido socioprodutivo no qual os agentes se especializam, cooperam, trocam informações, aprendem e compartilham um projeto comum, conforme preconizado por Amorim (1998), Martens, Freitas e Andres (2011) e Marçal et al (2012), no tocante à consequência da atividade empreendedora, também representa, com fidelidade, as etapas de construção do projeto, com destaque para a construção das redes de agentes e de representantes e para a contratação da agência de publicidade e propaganda, além do network com clientes e distribuidores do produto.

\subsection{Tema Aprendizagem}

Noção de aprendizagem organizacional como processo contínuo de apropriação e geração de novos conhecimentos nos níveis individual, grupal e organizacional, envolvendo todas as formas de aprendizagem - formais e informais - no contexto organizacional, alicerçado em uma dinâmica de reflexão e ação sobre as situações-problema e voltado para o desenvolvimento de competências. O contexto é constituído por complexa trama de referências, como o intercâmbio de informações e ideias, dentre outros elementos que, em longo prazo, podem auxiliar a configurar as práticas e o saber dos indivíduos e a determinar uma arquitetura social para este saber (ANTONELLO, 2005).

No processo de aprendizagem e no desenvolvimento das estratégias organizacionais, três elementos fundamentais podem ser identificados na agenda da estratégia como prática: (1) a prática, práxis ou o trabalho da estratégia; (2) os praticantes, estrategistas ou trabalhadores da estratégia; (3) as práticas: ferramentas, artefatos, tecnologias, linguagem, discursos que os praticantes utilizam no trabalho da estratégia (WHITTINGTON, 2006, p. $621)$.

A perspectiva da prática e as várias interpretações que podem ser feitas por meio dela, na análise tanto da aprendizagem como da estratégia, apresenta três aspectos em comum: a) preocupação voltada para as pessoas e suas atividades, ao invés de somente para as organizações como um todo; b) preocupação com as habilidades e a aprendizagem envolvidas neste processo, quando as pessoas realizam suas atividades; c) proposição da natureza fundamentalmente social de atividades, competências e aprendizagem das pessoas, como correção de uma tendência excessiva ao individualismo (WHITTINGTON, 2001, p. 3).

REAd | Porto Alegre - Edição 84 - N 2 - Maio / Agosto 2016 - p. 543 - 571 


\section{NO JOGO DO MERCADO: O CASO DE UMA STARTUP GAÚCHA}

\subsection{Caracterizando os estrategistas sob análise}

De acordo com Whittington (2003), a divisão de trabalho, o conhecimento, os interesses de cada indivíduo no fazer a estratégia, ainda são nebulosos. Tanto Cristiano como Marsal possuíam experiência prévia em atividades vinculadas à indústria criativa, portanto já tinham conhecimento sobre o funcionamento do referido mercado, bem como dos riscos que o ele oferecia, principalmente para empresas iniciantes.

No entanto, no segmento de produção de jogos digitais, seu conhecimento era mais de natureza técnica, de elaboração do que de mercado. Ambos conheciam muito bem a maioria das facetas relacionadas ao planejamento e à elaboração dos jogos digitais, mas as nuances e os detalhes do lançamento dos produtos no mercado, bem como as técnicas de gestão relacionadas com o suporte à operação, como finanças e marketing, não eram de seu domínio.

Considerando que, nas empresas, os estrategistas sintetizam e interpretam as práticas disponíveis no campo da estratégia, inicialmente Cristiano e Marsal, como estrategistas do novo empreendimento, reproduzem e não transformam/desenvolvem o estoque de práticas que poderão ser acessadas na próxima 'rodada' da sua práxis. Estão engajados em uma série de atividades cotidianas que constituem a práxis da estratégia, quando estrategizam. No entanto, eles deveriam não só utilizar, mas também alterar/atualizar o conjunto de práticas disponíveis no contexto social mais amplo. Ao deixar determinada prática, o indivíduo necessariamente não leva consigo essas formas de ver o mundo e de agir em sua plenitude. Ao engajar-se em nova prática, em novo contexto, o estrategista terá de aprender a executá-la segundo novas condições.

\subsection{Descrevendo a práxis desses estrategistas}

As práticas podem ser entendidas como hábitos, artefatos e modos de agir socialmente definidos, pelos quais o conjunto estruturado de atividades estratégicas é continuamente reconstruído. As práticas funcionam como uma espécie de infraestrutura, sob a qual o fazer da estratégia acontece (WHITTINGTON, 2003). Por exemplo, quando se constatou a fragilidade do jogo, no qual haviam sido investidos meses de trabalho e recursos financeiros relevantes, devido ao pagamento a profissionais especializados, além dos gastos com estrutura 


\section{Dusan Schreiber, Cristiano Max Pereira Pinheiro, Marsal Ávila Alves Branco, Cláudia Simone Antonello \& Deise Land}

interna e do esforço na divulgação, a descontinuidade da operação, naquele momento, foi a melhor estratégia a ser adotada. As ações e as conversações estabelecidas pelos estrategistas em episódios específicos e nas interações cotidianas localizadas no fazer estratégia complementam-se.

Pode-se presumir que esses interesses específicos se constituem de entendimentos, regras e estruturas específicas de uma prática que governa formas consideradas legítimas e desejáveis de se ver o mundo e de agir (WHITTINGTON, 2003). Entendimentos, regras e estruturas assumem, portanto, diferentes configurações não só entre diferentes práticas (estrategizar), mas também entre os diferentes usos dessas práticas, por exemplo, estrategizar no segmento X ou Y, na empresa Z ou W, no Rio de Janeiro ou no Rio Grande do Sul.

Este novo foco conceitual foi evidenciado quando os dois empreendedores decidiram descontinuar o modelo de negócios baseado na prestação de serviços a clientes corporativos, para se dedicar à produção de um jogo próprio, a ser colocado no mercado. Foi assim que a empresa ganhou notoriedade e os dois sócios obtiveram destaque, passando a atuar em interação com os governos federal e estadual, contribuindo para o estímulo à indústria de jogos digitais, por meio da definição do marco regulatório.

Ao lançar os olhos sobre essas práticas do campo da estratégia, interessa particularmente compreender quais são e como se originaram conceitos, ferramentas, tecnologias e receitas, que vencem a corrida contra os concorrentes, institucionalizam-se e passam a ser utilizadas correntemente (SANTOS, SETTE, \& TURETA, 2006).

\subsection{Discutindo as características gerais do contexto onde se insere o negócio}

De acordo com Whittington (2004), tem-se atribuído pouca atenção às práticas discursos legitimados, ferramentas, modos de proceder - do campo institucional no qual a organização se insere e seus impactos no nível micro de suas atividades. Os gerentes podem ser capturados em sistemas de crenças mais amplos e suas possibilidades de ação restringidas por forças institucionais. Como expõem os institucionalistas e os teóricos críticos, as microatividades podem ser facilmente dominadas por forças macrossociais (WHITTINGTON, 2004, p. 8).

Os dois empreendedores, por exemplo, dominavam muito bem o processo operacional, desde a concepção até a produção de jogos digitais. Apesar de não possuírem o 


\section{NO JOGO DO MERCADO: O CASO DE UMA STARTUP GAÚCHA}

mesmo nível de conhecimento sobre o funcionamento do mercado, buscaram as informações sobre ele, através de relatos de empresários que já trabalhavam no meio, em toda a cadeia, e de dados macro e microeconômicos disponibilizados nos sites governamentais e paragovernamentais. Todos os dados coletados e trabalhados no formato de pesquisa de mercado sugeriam boas possibilidades de negócio. Contudo, posteriormente, foram pegos de surpresa por algumas variáveis como a demora no retorno do mercado, a acirrada competição global, os custos não previstos para a comercialização do produto.

Em outra situação, os empreendedores privilegiaram, através da alocação de recursos, alguns aspectos do jogo, como estética e qualidade da narrativa, que, mais tarde, descobririam que não eram tão valorizados pelos consumidores. Em consequência perderam para jogos que haviam investido em aspectos mais valorizados como 'jogabilidade' e que eram mais lúdicos.

La Ville e Mounoud (2004) propuseram um esquema conceitual na tentativa de explicitar as ligações entre micro e macrocontextos. Nesse modelo, os macrocomponentes são conceituados como discursos e estruturas dominantes da estratégia, que fornecem os textos para a ação estratégica. Nesse nível estão os gurus, os modismos, as instituições sociais, econômicas e políticas envolvidas na produção e na dominação do campo da estratégia.

\subsection{Analisando como os estrategistas aprendem}

O que interessa mais, nesse caso, não são influências estruturais, esquemas cognitivos preconcebidos ou normas estabelecidas (JARZABKOWSKI, 2004). As práticas existentes são adaptadas para satisfazer interesses, desejos e emoções particulares de uma organização ou de uma prática específica dessa organização. Por exemplo, Cristiano já tinha trabalhado anteriormente em outros setores econômicos e tinha interesse em constituir um projeto empresarial, baseado em novos conceitos e paradigmas. Anteriormente, tinha realizado, entre outros, vários trabalhos nas áreas de publicidade e propaganda, de editoração, todos com sucesso. Ele sabia que o mercado muda constantemente e que o novo projeto precisaria de novo modelo de negócios para se adaptar ao novo contexto.

Essa liberdade de ação é descrita por Jarzabkowski (2005) como a dimensão práticoavaliativa da agência. Trata-se da capacidade de realizar o trabalho nas contingências específicas e exigidas do aqui-agora. Em meio às crises diárias das rotinas, as quais surgem

REAd | Porto Alegre - Edição 84 - N 2 - Maio / Agosto 2016 - p. 543 - 571 


\section{Dusan Schreiber, Cristiano Max Pereira Pinheiro, Marsal Ávila Alves Branco, Cláudia Simone Antonello \& Deise Land}

diante da variedade de interpretações e de conhecimentos que os agentes humanos envolvidos têm de enfrentar no calor da situação (RECKWITZ, 2002), podem ocorrer processos de aprendizagem.

Tanto Cristiano como Marsal procuraram estabelecer contatos no mercado com o intuito de averiguar o ambiente para investir na constituição da empresa, no entanto algumas condições do mercado haviam-se alterado completamente, com pouco espaço para novos entrantes. A sabedoria da prática relaciona tanto a agência iterativa - que diz respeito à reprodução pelos atores, de modelos existentes para o pensar e o agir estrategicamente (adaptação) - quanto a projetiva - que tem uma conotação voluntarista de escolha e intenção estratégica (mudança) - e abarca a possibilidade de aprendizado e descobertas.

$\mathrm{O}$ ato de exercer cada uma envolve o exercício de julgamento em tempo real, feito face a considerável ambiguidade, incerteza e conflito, em que meios e fins, algumas vezes, se contradizem, gerando consequências não intencionais que requerem mudança de estratégia e direção (WILSON \& JARZABKOWSKI, 2004, p. 13). Por exemplo, no decorrer da realização de uma pesquisa, os empreendedores identificaram, pela experiência inicial da empresa, que, com a atividade de prestação de serviços, não teriam como crescer e se destacar no mercado, devido à reduzida margem e ao grande número de entrantes. A margem de contribuição significativa, na percepção dos empresários, só seria possível através do lançamento de um produto próprio no mercado, o que fizeram, porém sem obter sucesso. Contudo, eles ganharam a experiência necessária para empreender uma nova tentativa.

\section{REFERÊNCIAS}

ABSTARTUP - ASSOCIAÇÃO BRASILEIRA DE STARTUP. Disponível em: <http://www.abstartups.com.br/category/duvidas>. Acesso em: 05 mar. 2014.

ADMINISTRADORES ONLINE. Disponível em:

$<$ http://www.administradores.com.br/noticias/administracao-e-negocios/especial-startupscomo-a-easy-taxi-se-transformou-no-maior-app-de-servicos-mobile-do-mundo/84513/>. Acesso em: 27 fev. 2014.

AMORIM, M. A. Clusters como estratégia de desenvolvimento industrial no Ceará. Fortaleza: Banco do Nordeste - ETENE. 1998.

ANTONELLO, C. S. A metamorfose da aprendizagem organizacional: um visão crítica. In R. Ruas, C. S. Antonello, \& L. H. Boff (Eds.). Os novos horizontes de gestão: aprendizagem organizacional e competências (pp. 10-33). Porto Alegre: Bookman, 2005. 


\section{NO JOGO DO MERCADO: O CASO DE UMA STARTUP GAÚCHA}

BRITTO, F., \& WEVER, L. (2003). Empreendedores brasileiros: vivendo e aprendendo com grandes nomes. Rio de Janeiro: Campus, 2003.

Drucker, P. F. (2002). Inovação e espírito empreendedor: prática e princípios (C. Malferrari, Trad.). São Paulo: Pioneira. (Obra original publicada em 1987).

EXAME - PLATAFORMA ONLINE. Disponível em:

$<$ http://exame.abril.com.br/tecnologia/noticias/para-a-easy-taxi-2014-e-o-ano-do-pagamentodigital>. Acesso em: 27 fev. 2014.

FILARDI, L. F., \& SOARES, L. M. Planejamento e criação de novas empresas: uma análise das causas da mortalidade precoce de novos negócios. Anais do Congresso Latino-Americano de Estratégia, Camboriú, SC, Brasil, 17, 2004.

GASPAR, F. Fomentar o empreendedorismo através do capital de risco e da incubação de empresas: um estudo empírico em Portugal. Revista Economia Global e Gestão, n. 2, p. 71 84, 2008.

GITAHY, Y. O que é uma start up? Portal Exame, 2010. Disponível em:

$<$ http://exame.abril.com.br/pme/noticias/o-que-e-uma-startup?page=2>. Acesso em 05 mar. 2014.

GEM (GLOBAL ENTREPRENEURSHIP MONITOR). Empreendedorismo no Brasil. 2012. Disponível em: <http://www.ibqp.org.br/gem/>. Acesso em: 13 out. 2013.

GUIMARÃES, Sônia M. K.; AZAMBUJA, Lucas Rodrigues. Empreendedorismo high-tech no Brasil: Condicionantes econômicos, políticos e culturais. Revista Sociedade e Estado, Vol. 25, No 1, Janeiro a Abril de 2010.

HARTMANN, Victor Hugo Pereira. Startup: uma nova forma de empreender. Brasília, 2013. Trabalho de Conclusão (Graduação em Administração de Empresas) - Centro Universitário de Brasília.

JARZABKOWSKI, P. Strategy as practice: recursiveness, adaptation, and practices-in-use. Organization Studies, 25(4), 529-560, 2004.

LA VILLE, V. I., \& MOUNOUD, E. What do we mean by strategy as practice? Proceedings of the EGOS Conference, Ljubljana, Slovenia, 19, 2004.

MACULAN, A. M. Ambiente empreendedor e aprendizado das pequenas empresas de base tecnológica. In H. M. Lastres, J. E. Cassiolato, \& M. L. Maciel (Eds.). Pequena empresa: cooperação e desenvolvimento local (pp. 311-326). Rio de Janeiro: Relume Dumjará, 2003.

MARÇAL, Maria Christianni Coutinho; MELLO, Sérgio C. Benício de; GUERRA, José Roberto Ferreira; ROCHA, Denis Deyvison Soares da. A perspectiva dialógica no agir empreendedor: um estudo de caso em uma Lan House. REAd, edição 73, no 3, setembro/dez. 2012, p.813-828

MARMER, Max; HERRMANN, Bjoern Lasse; BERMAN, Ron. Startup genome report: a new framework for understanding why startups succeed. [s.l., s. n.], 2012.

REAd | Porto Alegre - Edição 84 - Nº 2 - Maio / Agosto 2016 - p. 543 - 571 
Dusan Schreiber, Cristiano Max Pereira Pinheiro, Marsal Ávila Alves Branco, Cláudia Simone Antonello \& Deise Land

MARTENS, Cristina Dai Prá; FREITAS, Henrique Mello Rodrigues de; ANDRES, Rafael. Desenvolvimento da orientação empreendedora em empresas de software: proposições preliminares. REAd, edição 69, vol. 17, n 2, maio/agosto 2011, p.424-450

RECKWITZ, A. Toward a theory of social practices: a development in culturalist theorizing. European Journal of Social Theory, 5(2), 243-263, 2002.

SANTOS, S. A. Empreendedorismo de base tecnológica: evolução e trajetória. 2. ed. Maringá: Unicorpore, 2005.

SANTOS, L. L. S., SETTE, R. S., \& TURETA, C. A Estratégia como uma prática social: em busca do que seja "fazer estratégia". Anais do Encontro Nacional da Associação Nacional de Pós-Graduação e Pesquisa em Administração, Salvador, BA, Brasil, 30, 2006.

SECRETARIA DA ECONOMIA CRIATIVA. Políticas, diretrizes e ações, 2011-2014. Brasília: Ministério da Cultura, 2011.

SILVA, C. G. et al.. O perfil dos empreendedores nas startups: um estudo de caso na incubadora tecnológica de Santa Maria. In: $2^{\circ}$ Fórum internacional ecoinovar, Santa Maria, 2013. Anais... Santa Maria: 2009.

SCHUMPETER, Joseph Alois. Teoria do desenvolvimento econômico: uma investigação sobre lucros, capital, crédito, juro e o ciclo econômico . São Paulo, SP: Abril Cultural, 1982. xv, 169 p.

THE ECONOMIST. Especial Report: Tech Startups. Jan. 2014. Disponível em<http://media.economist.com/sites/default/files/sponsorships/\%5BKY56b\%5DHuawei/180 114_SR.pdf $>$. Acesso em: 18 mai 2014.

WHITTINGTON, R. Learning to strategise: problems of practice. Proceedings of the EGOS Conference, Lyon, France, 16, 2001.

WHITTINGTON, R. The work of strategizing and organizing: for a practice perspective. Strategic Organization, 1(1), 117-126, 2003.

WHITTINGTON, R. Strategy after modernism: recovering practices. European Management Review, 1(1), 62-68, 2004.

WHITTINGTON, R. Completing the practice turn in strategy research. Organization Studies, 27(5), 613-634, 2006.

WILSON, D. C., JARZABKOWSKI, P. Thinking and acting strategically: new challenges for interrogating strategy. European Manage Management Review, 1(1), 14-20, 2004.

XAVIER, W. G.; CANCELLIER, E. L. P. L. Atividades de monitoramento em empresas de startup de base tecnológica na indústria do turismo. Análise, Porto Alegre, v. 19, n. 2, p. 107 119, jul./dez 2008. 